LETTER TO JMG

\title{
Increased recurrence risk in congenital disorders of glycosylation type la (CDG-la) due to a transmission ratio distortion
}

\author{
E Schollen, S Kjaergaard, T Martinsson, S Vuillaumier-Barrot, M Dunoe, L Keldermans, N Seta, \\ G Matthijs
}

C ongenital disorders of glycosylation type Ia or CDG-Ia (MIM 212065) is the most common type of a group of recessive disorders characterised by deficient glycosylation. ${ }^{1}$ The disease is caused by mutations in the PMM2 gene, coding for a phosphomannomutase (PMM). PMM converts mannose-6-phosphate to mannose-1-phosphate, a precursor of the mannosyl donor in $\mathrm{N}$-and O-glycosylation and the synthesis of GPI anchors. PMM deficiency leads to underglycosylation and altered processing of the $\mathrm{N}$-glycans in serum proteins of CDG-Ia patients. ${ }^{2}{ }^{3}$

A plethora of different mutations, mostly missense mutations, results in a clinical spectrum ranging from mild to very severe with neonatal death. ${ }^{4}$ A founder effect for the mutation F119L (c.357C $\rightarrow$ A) in the Scandinavian population results in a more homogenous group of patients in these countries. ${ }^{6}$

Around $37 \%$ of CDG-Ia patients are heterozygous for the missense mutation Rl41H (c.422G $\rightarrow$ A), which has never been observed in the homozygous state. ${ }^{78}$ The very low residual $(<1 \%)$ activity of the mutant $\mathrm{Rl} 14 \mathrm{lH}$ protein is probably not sufficient for viability. ${ }^{9}$ In spite of this genetic lethality, the carrier frequency for $\mathrm{R} 141 \mathrm{H}$ is rather high, being $1 / 72$ in the Dutch and Danish populations. ${ }^{8}$

Without a mechanism counteracting the constant loss of recessive disease alleles, this $\mathrm{R} 141 \mathrm{H}$ mutation would have vanished. The most obvious explanations for its persistence are a high mutation rate, genetic drift, a heterozygous advantage, or a transmission distortion.

The first possibility has been discounted by the observation that, in most patients and carriers, the mutation is associated with a specific haplotype, and thus represents a single, ancestral event. ${ }^{68}$ Based on linkage disequilibrium with marker Dl6S3020 the most recent common ancestor was calculated to have lived at least 250 generations ago (R Colombo and E Schollen, unpublished data). Genetic drift could be an important factor in small populations and for non-lethal mutations. For a severe mutation like R141H, found in CDG-Ia patients from all over Europe, ${ }^{5}$ genetic drift can be neglected.

A heterozygous advantage has been postulated for several recessive disorders (for example, cystic fibrosis, ${ }^{10}$ phenylketonuria, ${ }^{11}$ sickle cell anaemia, ${ }^{12}$ and factor $\mathrm{V}$ deficiency ${ }^{13}$ ), although the exact nature of the selective mechanism is often unknown. For CDG-Ia, Freeze and Westphal ${ }^{14}$ hypothesised that there could be a protective effect against infective viruses such as hepatitis virus $\mathrm{B}$ and $\mathrm{C}$ in carriers of a PMM2 mutation. Such viruses rely heavily on host $\mathrm{N}$-glycosylation for reproduction.

Cumulative data of several years of prenatal diagnosis for CDG-Ia, however, present evidence for a transmission ratio distortion.

\section{Key points}

- Congenital disorders of glycosylation type la (CDG-la) is a rare recessive metabolic disease, caused by phosphomannomutase deficiency.

- In 92 independent pregnancies among couples at risk for CDG-la, genotyped in the context of prenatal diagnosis, the percentage of affected fetuses $134 \%$; $31 / 92, p=0.039$ ) is higher than expected based on Mendel's second law.

- The transmission ratio distortion might explain the relatively high carrier frequency of the frequent $\mathrm{R} 141 \mathrm{H}$ mutation in the PMM2 gene. It suggests that the drive of the mutated alleles relates to a reproductive advantage at the stage of gametogenesis, fertilisation, implantation, or embryogenesis, rather than to resistance to environmental factors during infant or adult life.

- The practical implication of this observation is an increased recurrence risk, close to 1 in 3 rather than 1 in 4, in CDG-la families.

\section{RESULTS AND DISCUSSION}

Over the last 6 years, the four centres involved in this study have performed molecular prenatal diagnosis for 92 pregnancies in 59 CDG-Ia families from different European countries (53), the US (four), Canada (one), and Argentina (one) (table 1). The parental and prenatal samples were genotyped for the specific, familial mutations. Maternal contamination of the fetal tissue has been excluded in the majority of the samples using polymorphic markers localised on different chromosomes. Since only independent pregnancies were taken into account, one expects a distribution according to Mendel's second law. However, a predominance of affected fetuses $(31 / 92 ; 34 \%$, binomial distribution $\mathrm{p}(\mathrm{X} \geqslant 34 \%)=0.039)$ was observed when compared to carriers of the maternal disease allele $(22 / 92 ; 24 \%)$, carriers of the paternal disease allele (20/92; 22\%), and non-carriers (19/92, $20 \%$ ) (table 2). A similar transmission ratio distortion is also observed within the homogeneous group of families with the specific mutations F119L and R141H with 16 compound heterozygotes in 42 pregnancies (38\%, table 2 ).

The practical implication of this segregation distortion is an increased recurrence risk in CDG-Ia families ranging from $38 \%$ in Scandinavian families to $34 \%$ in other European

Abbreviations: $95 \% \mathrm{Cl}, 95 \%$ confidence interval; CDG-la, congenital disorders of glycosylation type la; PMM, phosphomannomutase 
Table 1 Genotypes of 92 pregnancies in 59 families

\begin{tabular}{|c|c|c|c|c|c|c|}
\hline $\begin{array}{l}\text { Number of } \\
\text { families }\end{array}$ & $\begin{array}{l}\text { Maternal } \\
\text { mutation }(\mathrm{Mm})\end{array}$ & $\begin{array}{l}\text { Paternal } \\
\text { mutation (Mp) }\end{array}$ & $\mathrm{N} / \mathrm{N}$ & $\mathrm{N} / \mathrm{Mm}$ & $\mathrm{N} / \mathrm{Mp}$ & $M m / M p$ \\
\hline 10 & F119L & $\mathrm{R} 141 \mathrm{H}$ & 2 & 5 & 5 & 8 \\
\hline 14 & $\mathrm{R} 141 \mathrm{H}$ & F119L & 5 & 3 & 6 & 8 \\
\hline 1 & G15R & $\mathrm{R} 141 \mathrm{H}$ & 1 & & & \\
\hline 1 & D65Y & $\mathrm{R} 141 \mathrm{H}$ & & 1 & & 1 \\
\hline 2 & V129M & $\mathrm{R} 141 \mathrm{H}$ & 2 & & & \\
\hline 1 & El39K & $\mathrm{R} 141 \mathrm{H}$ & & & 1 & \\
\hline 1 & R162W & $\mathrm{R} 141 \mathrm{H}$ & & & & 1 \\
\hline 2 & D188G & $\mathrm{R} 141 \mathrm{H}$ & 2 & & & 1 \\
\hline 3 & V231M & $\mathrm{R} 141 \mathrm{H}$ & 1 & 1 & 1 & \\
\hline 1 & T237M & $\mathrm{R} 141 \mathrm{H}$ & & & 1 & \\
\hline 1 & $\mathrm{R} 141 \mathrm{H}$ & D65Y & & 1 & & 1 \\
\hline 1 & $\mathrm{R} 141 \mathrm{H}$ & P69S & & 1 & & \\
\hline 1 & $\mathrm{R} 141 \mathrm{H}$ & A108V & & & 1 & \\
\hline 1 & $\mathrm{R} 141 \mathrm{H}$ & P1 13A & 1 & & & \\
\hline 2 & $\mathrm{R} 141 \mathrm{H}$ & P113L & & 1 & 1 & 1 \\
\hline 2 & $\mathrm{R} 141 \mathrm{H}$ & E139K & 1 & 1 & 1 & \\
\hline 1 & $\mathrm{R} 141 \mathrm{H}$ & D188G & 1 & & 1 & 4 \\
\hline 2 & $\mathrm{R} 141 \mathrm{H}$ & V231M & 1 & & & 2 \\
\hline 1 & $\mathrm{R} 141 \mathrm{H}$ & $\mathrm{NI}$ & & 1 & & \\
\hline 1 & F119L & G117R & 1 & 2 & & \\
\hline 1 & F119L & V231M & & 1 & & \\
\hline 1 & D65Y & R123Q & & & & 1 \\
\hline 1 & c.389_390delC & T237M & & 1 & & \\
\hline 1 & $\mathrm{~V} 129 \mathrm{M}$ & $\mathrm{IVS} 3+2 \mathrm{~T} \rightarrow \mathrm{C}$ & & & & 1 \\
\hline 1 & F157S & V231M & & & & 1 \\
\hline 1 & R162W & R123Q & & 1 & 2 & \\
\hline 1 & $\mathrm{H} 218 \mathrm{~L}$ & $\mathrm{IVS} 3+2 \mathrm{~T} \rightarrow \mathrm{C}$ & & & & 1 \\
\hline 1 & V231M & D188G & & 1 & & \\
\hline 1 & V231M & I120T & 1 & & & \\
\hline 1 & $\mathrm{NI}$ & L32R & & 1 & & \\
\hline
\end{tabular}

families. If this observation can be confirmed in a larger study, this might change the way in which these families are genetically counselled. A recurrence risk of 1 in 3 instead of 1 in 4 might affect the reproductive choices in families at risk.

Such a deviation of Mendel's second law has been described before for dominant diseases, caused by trinucleotide expansions, ${ }^{15}{ }^{16}$ but has, to our knowledge, not been previously described for any recessive or metabolic disorder. Most of the reports on meiotic drive of trinucleotide expansions have been criticised on statistical grounds, often because of failure to correct for ascertainment bias. ${ }^{17}$ In contrast, no bias is expected in the population used in this study since only independent pregnancies were included.

Translating the fetal genotypes into transmitted alleles means a positive selection of $57 \%$ (104/184, binomial distribution $\mathrm{p}(X \geqslant 57 \%)=0.045)$ for mutation bearing alleles compared to normal alleles (table 3 ). The preferential transmission of the mutated alleles, which amounts to 56\% (table 3) among carriers of R141H, can account for the high carrier frequency of this mutation in the European population. The same observation could explain the founder effect for F119L in the Scandinavian population. ${ }^{18}$

Table 2 Distribution of genotypes

\begin{tabular}{|c|c|c|c|c|c|}
\hline $\begin{array}{l}\text { Sample } \\
\text { group }\end{array}$ & $\begin{array}{l}\text { Normal, } \\
\text { n (\%) }\end{array}$ & $\begin{array}{l}\text { Carrier } \\
\text { maternal } \\
\text { mutation, } \\
\text { n (\%) }\end{array}$ & $\begin{array}{l}\text { Carrier } \\
\text { paternal } \\
\text { mutation, } \\
\text { n (\%) }\end{array}$ & $\begin{array}{l}\text { Affected, } \\
\text { n (\%; } \\
95 \% \mathrm{Cl})\end{array}$ & $\mathbf{p}^{*}$ \\
\hline All samples & $19(20)$ & $22(24)$ & $20(22)$ & $\begin{array}{l}31(34 ; \\
24 \text { to } 44)\end{array}$ & 0.039 \\
\hline $\begin{array}{l}\text { Families with } \\
\text { mutations } \\
\text { F119L and } \\
\text { R141H }\end{array}$ & $7(17)$ & 8 (19) & $11(26)$ & $\begin{array}{l}16(38 ; \\
23 \text { to } 54)\end{array}$ & 0.041 \\
\hline
\end{tabular}

Table 3 Transmission of mutated versus normal alleles

\begin{tabular}{|c|c|c|c|c|}
\hline $\begin{array}{l}\text { Sample } \\
\text { group }\end{array}$ & $\begin{array}{l}\text { Transmission } \\
\text { of normal } \\
\text { allele }\end{array}$ & $\begin{array}{l}\text { Transmission } \\
\text { of mutated } \\
\text { allele }\end{array}$ & $\begin{array}{l}\text { Ratio, \% } \\
(95 \% \mathrm{Cl})\end{array}$ & $\mathbf{p}^{*}$ \\
\hline All samples & 80 & 104 & $\begin{array}{l}57 \% \\
(49 \text { to } 64)\end{array}$ & 0.045 \\
\hline $\mathrm{R} 141 \mathrm{H}$ & 67 & 87 & $\begin{array}{l}56 \% \\
(48 \text { to } 64)\end{array}$ & 0.063 \\
\hline F119L & 38 & 54 & $\begin{array}{l}59 \% \\
(48 \text { to } 69)\end{array}$ & 0.059 \\
\hline
\end{tabular}

This inference assumes that selection applies for both homozygotes and heterozygotes. From the data in the CDG-Ia families, however, we cannot conclude whether the preferential transmission results from selection of the mutated alleles in the affected fetuses or whether there is also selection in heterozygous compared to healthy carriers. The nearly normal number of carriers of either the maternal or paternal allele could be explained by the flattening of the positive selection of the mutated alleles with the negative selection of the wild type alleles, a hypothesis that also fits with the low number of normal fetuses. The offspring of couples where only one parent carries a PMM2 mutation would be a good population to test this hypothesis. The limited data which we have on this kind of population is compatible with this hypothesis: in $58 \%$ of the meioses the mutation was transmitted $(\mathrm{p}(\mathrm{X} \geqslant 58 \%)=0.161$, 95\% confidence interval $(95 \% \mathrm{CI})=43$ to 72$)$. The data are statistically not significant because of the low numbers.

Given the role of glycosylation in all aspects of human reproduction, we suggest a functional advantage directly related to glycosylation deficiency as a possible selection system. The selection can take place at all stages of reproduction and the possible mechanisms include gamete 
selection, postzygotic viability selection, or meiotic drive. A clear distinction between the above mechanisms cannot be made on the basis of our data, but there is circumstantial evidence for selection at the gamete level. As indicated above, the distribution of the four different genotypes in the offspring of CDG-Ia families and the slight preponderance of heterozygous offspring in families in which only one parent is a carrier, are compatible with a positive selection of mutation bearing gametes.

If selection occurs at the gamete level, it might well be that the selective transmission is gender and/or mutation dependent. It has been shown before that the degree of aberrant and hypoglycosylation of serum proteins depends on the patients' mutations. ${ }^{3}$ In the F119L/R141H subpopulation, both paternal and maternal transmission is in favour of the mutated alleles (64\% (27/42) and 57\% (24/42), respectively). In families with a combination of mutations other than F119L/R141H, mothers preferentially transmit their mutated alleles $(59 \%, 29 / 50)$, but no preference is observed among the paternal alleles $(48 \%, 24 / 50)$. In the overall CDG-Ia population, no significant difference is observed between transmission of the moderate mutation F119L (59\%) and the severe mutation $\mathrm{R} 141 \mathrm{H}(56 \%)$ (table 3 ). The variety of the other mutations is too large for statistically significant figures (table 1). The combined data are compatible with selection pressure at the gamete level, possibly with a different mechanism for spermatozoa and oöcytes.

Preliminary results of single cell haplotyping of sperm ejaculates of two healthy carriers of PMM2 mutations, showed a normal ratio $(50 \%, 95 \% \mathrm{CI}=37$ to 63$)$ of mutation bearing versus normal sperm cells for an F119L carrier. The ejaculate of the R141H carrier contained 54\% mutation bearing sperms $(p(X \geqslant 54 \%)=0.25,95 \% C I=42$ to 66$)$ (S Kjaergaard and M Dunoe, unpublished data).

Even if these results are consistent with selection of sperm and oöcytes during gametogenesis or at fertilisation and even though late post-zygotic selection favouring often severely affected fetuses is hard to imagine, an advantage of aberrant glycosylation during implantation and early development cannot be excluded.

Meiotic drive due to molecular events also has to be considered as a possible explanation. As an example, Jeffreys and Neumann reported on a reciprocal crossover asymmetry in a human recombination hotspot at the major histocompatibility class II region as a possible mechanism for meiotic drive. ${ }^{19}$ The founder effect of the F119L mutation ${ }^{18}$ and the strong linkage disequilibrium observed between the mutation $\mathrm{R} 141 \mathrm{H}$, the marker D16S3020 located $32 \mathrm{~kb}$ distal of this position (Ensembl contig AC007218.6.1.193220), and a single nucleotide polymorphism in intron 5 of the $P M M 2$ gene (IVS5+22 A/T) argue against this possibility in CDG-Ia.

Finally, it might well be that a specific allele at another locus, in close proximity to the PMM2 gene, is responsible for this transmission distortion rather than the PMM2 mutations themselves. However, this would invoke a combination of the specific allele at that locus with both the F119L and R141H mutation, which is unlikely.

What exactly mediates selection in terms of glycosylation remains to be solved. It could either be the hypoglycosylation per se or the appearance of aberrant glycoforms in glycosylation deficiencies. For example, in a study of the mannosidase IIx knockout mouse, Akama and coworkers have previously described a role in fertilisation of a specific, previously unknown oligosaccharide with three exposed GlcNAc residues as well as a core fucose residue. ${ }^{20}{ }^{21}$ Interestingly, two papers report increased fucosylation of the glycans in serum from CDG-Ia patients. ${ }^{23}$

In conclusion, this is the first time that preferential transmission has been documented for a recessive disorder.
One may wonder whether it is specific for CDG-Ia or whether it also exists in the other glycosylation disorders or even other metabolic disorders. Further investigation of this observation might provide new insight in the complex role of glycosylation in human fertilisation.

\section{ACKNOWLEDGEMENTS}

We gratefully acknowledge Professor R Vlietinck and Professor E Legius for advice on the statistical interpretation of the data.

\section{Authors' affiliations}

E Schollen, L Keldermans, G Matthijs, Center for Human Genetics, University of Leuven, Leuven, Belgium

S Kjaergaard, M Dunoe, Department of Clinical Genetics,

Rigshospitalet, Copenhagen, Denmark

T Martinsson, Department of Clinical Genetics, Göteborg University, Sahlgrenska University Hospital East, SE-41685 Göteborg, Sweden S Vuillaumier-Barrot, N Seta, Hôpital Bichat Claude Bernard AP-HP, Paris Cedex 18, France

This research was supported by grants from the Fund for Scientific Research (FWO, Flanders; grant 9.0243.98), from the Interuniversity Poles of Attraction Federal Program (grant P5/25), from the French Research Network on CDG GIS-Institut des Maladies Rares (GISMR0308), and from the European Commission (Fifth Framework Programme, contract QLG1-2000-00047 to EUROGLYCAN; http:// www.euroglycan.org).

Conflict of interest: none declared.

Correspondence to: Gert Matthiis, Center for Human Genetics, University of Leuven, Leuven, Belgium; Gert.Matthijs@ med.kuleuven.ac.be

Revised version received 29 June 2004

Accepted for publication 30 June 2004

\section{REFERENCES}

1 Jaeken J. Komrower Lecture. Congenital disorders of glycosylation (CDG): it's all in it! J Inherit Metab Dis 2003;26(2-3):99-118.

2 Mills K, Mills PB, Clayton PT, Mian N, Johnson AW, Winchester BG. The underglycosylation of plasma alpha 1-antitrypsin in congenital disorders of glycosylation type I is not random. Glycobiology 2003;13(2):73-85.

3 Callewaert N, Schollen E, Vanhecke A, Jaeken J, Matthijs G, Contreras R. Increased fucosylation and reduced branching of serum glycoprotein $\mathrm{N}$ glycans in all known subtypes of congenital disorder of glycosylation I. Glycobiology 2003;13(5):367-75.

4 Grunewald S, Schollen E, Van Schaftingen E, Jaeken J, Matthiis G. High residual activity of PMM2 in patients' fibroblasts: possible pitfall in the diagnosis of CDG-la (phosphomannomutase deficiency). Am J Hum Genet 2001;68(2):347-54

5 Matthiis G, Schollen E, Bjursell C, Erlandson A, Freeze H, Imtiaz F, Kiaergaard S, Martinsson T, Schwartz M, Seta N, Vuillaumier-Barrot S, Westphal V, Winchester B. Mutations in PMM2 that cause congenital disorders of glycosylation, type la (CDG-la). Hum Mutat 2000; 16(5):386-94

6 Erlandson A, Bjursell C, Stibler H, Kristiansson B, Wahlstrom J, Martinsson T. Scandinavian CDG-la patients: genotype/phenotype correlation and geographic origin of founder mutations. Hum Genet 2001;108(5):359-67.

7 Matthijs G, Schollen E, Van Schaftingen E, Cassiman JJ, Jaeken J. Lack of homozygotes for the most frequent disease allele in carbohydrate-deficient glycoprotein syndrome type 1A. Am J Hum Genet 1998;62(3):542-50.

8 Schollen E, Kjaergaard S, Legius E, Schwartz M, Matthiis G. Lack of HardyWeinberg equilibrium for the most prevalent PMM2 mutation in CDG-la (congenital disorders of glycosylation type la). Eur J Hum Genet 2000:8(5):367-71.

9 Pirard M, Matthiis G, Heykants L, Schollen E, Grunewald S, Jaeken J, van Schaftingen $E$. Effect of mutations found in carbohydrate-deficient glycoprotein syndrome type IA on the activity of phosphomannomutase 2. FEBS Lett 1999;452(3):319-22.

10 Prince A. The CFTR advantage - capitalizing on a quirk of fate. Nat Med 1998:4(6):663-4.

11 Krawczak M, Zschocke J. A role for overdominant selection in phenylketonuria? Evidence from molecular data. Hum Muta 2003:21(4):394-7.

12 Aidoo M, Terlouw DJ, Kolczak MS, McElroy PD, ter Kuile FO, Kariuki S, Nahlen BL, Lal AA, Udhayakumar V. Protective effects of the sickle cell gene against malaria morbidity and mortality. Lancet 2002;359(9314):1311-2.

13 Gopel W, Ludwig M, Junge AK, Kohlmann T, Diedrich K, Moller J. Selection pressure for the factor-V-Leiden mutation and embryo implantation. Lancet 2001;358(9289): 1238-9

14 Freeze $\mathrm{HH}$, Westphal $\mathrm{V}$. Balancing $\mathrm{N}$-linked glycosylation to avoid disease. Biochimie 2001;83(8):791-9. 
15 Ikeuchi T, Igarashi S, Takiyama $Y$, Onodera O, Oyake M, Takano $\mathrm{H}$, Koide $\mathrm{R}$, Tanaka H, Tsuji S. Non-Mendelian transmission in dentatorubralpallidoluysian atrophy and Machado-Joseph disease: the mutant allele is preferentially transmitted in male meiosis. Am J Hum Genet 1996:58(4):730-3.

16 Riess O, Epplen JT, Amoiridis G, Przuntek H, Schols L. Transmission distortion of the mutant alleles in spinocerebellar ataxia. Hum Genet 1997;99(2):282-4.

17 Teague JW, Morton NE, Dennis NR, Curtis G, McKechnie N, Macpherson JN Murray A, Pound MC, Sharrock AJ, Youings SA, Jacobs PA. FRAXA and FRAXE: evidence against segregation distortion and for an effect of intermediate alleles on learning disability. Proc Natl Acad Sci U S A 1998;95(2):719-24.
18 Biursell C, Wahlstrom J, Berg K, Stibler $\mathrm{H}$, Kristiansson B, Matthiis $\mathrm{G}$ Martinsson T. Detailed mapping of the phosphomannomutase 2 (PMM2) gene and mutation detection enable improved analysis for Scandinavian CDG type I families. Eur J Hum Genet 1998;6(6):603-11.

19 Jeffreys AJ, Neumann R. Reciprocal crossover asymmetry and meiotic drive in a human recombination hot spot. Nat Genet 2002;31(3):267-71.

20 Akama TO, Nakagawa H, Sugihara K, Narisawa S, Ohyama C, Nishimura S, O'Brien DA, Moremen KW, Millan JL, Fukuda MN. Germ cell survival through carbohydrate-mediated interaction with Sertoli cells. Science 2002:295(5552): 124-7.

21 Fukuda MN, Akama TO. The role of $\mathrm{N}$-glycans in spermatogenesis. Cytogenet Genome Res 2003;103(3-4):302-6. 